\title{
Analysis of the Accumulation of Pea enation mosaic virus Genomes in Seed Tissues and Lack of Evidence for Seed Transmission in Pea (Pisum sativum)
}

\author{
Gail Timmerman-Vaughan, Richard Larsen, Sarah Murray, Kevin McPhee, and Clarice Coyne
}

\begin{abstract}
First and third authors: New Zealand Institute for Plant \& Food Research Ltd., P.O. Box 4704, Christchurch 8140, New Zealand; second author: United States Department of Agriculture-Agricultural Research Service (USDA-ARS), The Vegetable and Forage Crop Research Unit, 24106 N. Bunn Rd., Prosser, WA 99350; fourth author: North Dakota State University, Department of Plant Sciences, P.O. Box 6050, Fargo 58108-6050; and fifth author: USDA-ARS Western Regional Plant Introduction Station, 59 Johnson Hall, WSU, Pullman, WA 99164-6402.
\end{abstract}

Accepted for publication 25 June 2009.

\begin{abstract}
Timmerman-Vaughan, G., Larsen, R., Murray, S., McPhee, K., and Coyne, C. 2009. Analysis of the accumulation of Pea enation mosaic virus genomes in seed tissues and lack of evidence for seed transmission in pea (Pisum sativum). Phytopathology 99:1281-1288.

Pea enation mosaic virus (PEMV) is an important virus disease of pea. International movement of commercial pea cultivars and germplasm can be problematic due to uncertainty about seed transmission of the viruses responsible for the disease. Whether PEMV is seedborne was assessed by collecting developing seed from infected plants and determining the relative concentrations of the PEMV-1 and PEMV-2 viral genomes using

The relative accumulation of PEMV- 1 and PEMV- 2 was $\approx 1,240$ and 13,000 times higher, respectively, in leaf than in embryo tissues. Accumulation of PEMV-1 and PEMV-2 RNA was also significantly higher in pod walls and seed coats than in cotyledons or embryo axes. No evidence was obtained for seed transmission of PEMV in pea. Although PEMV-1 and PEMV-2 genomic RNAs were found in developing seed, no PEMV symptoms were observed in the field on more than 50,000 plants from seed derived from PEMV-infected source plants. These data demonstrate that PEMV is seedborne in pea but do not support a previous report that PEMV is seed transmitted. Absence of seed transmission may result from the low abundance of PEMV viral genomes in embryo tissue.
\end{abstract} quantitative real-time reverse-transcription polymerase chain reaction.
Pea enation mosaic virus (PEMV) is an important virus disease of pea (Pisum sativum L.) with worldwide distribution, although it is not known to occur in New Zealand or Australia. Whether PEMV is seed transmitted is not well documented. Kovachevsky (16) reported early-season development of PEMV disease in fieldgrown seedlings derived from seed from infected plants, and concluded that this was due to seed transmission of PEMV in pea rather than de novo infection. However, no subsequent work has corroborated this observation. In a later description of PEMV, Skaaf and de Zoeten (27) cited Kovachevsky as reporting a low frequency $(1.5 \%)$ of seed transmission, although seed transmission was never quantified in the original Kovachevsky paper.

The biology of PEMV has been described $(18,27)$. The host range is primarily limited to members of the family Fabaceae, although it can be propagated on nonlegume hosts such as Gomphrena globosa, Chenopodium spp., and Nicotiana spp. PEMV is transmitted by a number of aphid species, most commonly the pea aphid (Acyrthosyphon pisum) and cowpea aphid (Aphis craccivora), and less commonly by the green peach aphid (Myzus persicae), potato aphid (Macrosiphum euphorbiae), and foxglove aphid (Aulacorthum solani). In the aphid, PEMV is transmitted in a circulative nonpropagative manner, is retained through molting, but is not transmitted to progeny. Some strains are mechanically transmissible.

Corresponding author: G. Timmerman-Vaughan

E-mail address: gail.timmerman-vaughan@ plantandfood.co.nz

\section{doi:10.1094/PHYTO-99-11-1281}

This article is in the public domain and not copyrightable. It may be freely reprinted with customary crediting of the source. The American Phytopathological Society, 2009
The symptoms of PEMV infection in pea include distorted plant growth, stunting, development of a distinctive yellow mosaic on leaves appearing as translucent flecks and vein clearing, characteristic windowing in the stipules and flowers, leaf chlorosis and leaf curl, enations on pods, and shriveled seed. Purpleflowered pea cultivars infected with PEMV often show color break symptoms displayed as attractive white streaking on the flowers. The most characteristic symptom of PEMV infection is the development of enations that are a result of hyperplastic outgrowths on leaf and pod surfaces. Pods from infected plants are often misshapen and seed set is markedly reduced.

The causal agents of the PEMV disease are two obligately symbiotic viral genomes, PEMV-1, the sole member of the Enamovirus genus within the Luteovirus family; and PEMV-2, a member of the Umbravirus genus $(10,12)$. A satellite RNA (RNA-3) is associated with PEMV-2 $(8,11)$. The PEMV-1 genome contributes the encapsidating coat protein gene and aphid transmissibility, while the PEMV-2 genome is responsible for mechanical transmissibility and systemic viral movement in the plant (25). Although PEMV is apparently unique, the Umbravirus Groundnut rosette virus (GRV) has a similar biology. In this case, the GRV genome and an associated satellite RNA are responsible for symptom production and long-distance movement, while Groundnut rosette assistor virus (GRAV), a Luteovirus sp., provides the capsid protein and aphid transmissibility functions (21). There is no evidence that the GRV/GRAV complex is transmitted through seed (21).

Approximately $20 \%$ of plant viruses can be seed transmitted (31) and include members of a number of plant virus families (20). Most seedborne viruses must become established in the host embryonic tissues for seed transmission to occur. An exception is 
Tobacco mosaic virus (TMV), where the virus has been shown to be associated with the seed coat but not the embryo (7), and seedlings have been reported to become infected from the seed coat at germination $(4,19)$. There are two routes for viruses to infect embryonic tissues, through (i) viral invasion of embryonic tissues following fertilization and (ii) the fusion of infected gametes, which may be either egg cells or pollen grains. The seedborne viral material also must survive desiccation and germination to establish an infection in seedlings. Plant genotype, virus genotype, the presence of other plant viruses, and environmental conditions can all influence seed transmission (19). Seed transmission of plant viruses has been studied in some detail in a number of systems including Barley stripe mosaic virus (BSMV) (13), Cucumber mosaic virus (14) and two pea viruses, Pea seed-borne mosaic virus (PSbMV) (22) and Pea early browning virus (30).

In this study, we have shown that PEMV is seedborne but have found no evidence of seed transmission in pea. Quantitative realtime reverse-transcription polymerase chain reaction (qRT-PCR) was used to estimate the relative abundance of PEMV-1 and PEMV-2 genomic RNA in tissues, including seed coats, cotyledons, and embryo axes dissected from developing seed from systemically infected pea plants. In addition, seed transmission was examined in an extensive breeder seed multiplication growout and by enzyme-linked immunosorbent assay (ELISA) testing of seedlings grown from seed harvested from infected pods.

\section{MATERIALS AND METHODS}

Plant material and viral isolates. A natural epidemic of PEMV occurred in the Pacific Northwest region in the United States during summer 2005 (6). Infected pea plants were sampled from field trial sites near Pullman, WA, and Central Ferry, WA. PEMV-infected stipule tissue for RNA extraction was obtained from the United States Department of Agriculture-Agricultural Research Service breeding trial of cv. Medora at the Washington State University Spillman Research Farm near Pullman. RNA extractions from pod wall and seed tissue (seed coat, cotyledon, and embryo axis) were also carried out on material from the same plants. Plant material for additional pod wall and seed tissue RNA extraction was obtained by transplanting infected buffer row plants (cv. Joel) from the Central Ferry trial into pots which were then grown and maintained outdoors under shade cloth at Washington State University in Pullman.
RNA extraction. Tissue for RNA extraction was placed on dry ice immediately after collection and stored at $-80^{\circ} \mathrm{C}$. Pod wall and seed dissections were carried out using flamed forceps and a new scalpel blade for every cut to avoid cross contamination. RNA was extracted by one of two methods. The RNeasy kit (Qiagen, Germantown, MD) was used following the manufacturer's instructions for a limited number of extractions, including those used for PEMV-1 and PEMV-2 partial sequence analysis. Most samples were extracted using Concert Plant RNA Reagent (Invitrogen, Carlsbad, CA) following the manufacturer's protocol. RNA concentrations were estimated by measuring absorbance at $260 \mathrm{~nm}\left(\mathrm{~A}_{260}\right)$ and quality was estimated by determining $\mathrm{A}_{260}: \mathrm{A}_{280}$ ratios.

Partial sequence analysis of viral isolates. Regions of the PEMV-1 and PEMV-2 genomes for PCR primer design were identified by aligning sequences from publicly available sequence databases using ClustalX ver. 1.8 (29) and BLAST algorithms (1). The accession numbers for PEMV-1 sequences used in alignments were NC_003629, Y09098, Z48507, AF082833, Y09100, and Y09099. PEMV-2 sequences used in alignments were NC_003853, AY007257, AY686696, and U03563. Primers were designed using Primer3 software (24), using the default settings, and are presented in Table 1.

RT-PCR amplification of PEMV-1 and PEMV-2 fragments for use in sequence analysis was carried out as follows. RNA extracted from infected stipules was diluted 1:5 in RNase-free water. RT-PCR reactions were set up in $20-\mu$ reactions using the Superscript III Platinum One-Step qRT-PCR System (Invitrogen), with each primer added to a final concentration of $0.8 \mu \mathrm{M}$ and with the addition of $1 \mu \mathrm{l}$ of diluted RNA. PCR was carried out in an ABI 9700 thermal cycler (Applied Biosystems, Foster City, CA) using the following parameters: 1 cycle of $50^{\circ} \mathrm{C}$ for $30 \mathrm{~min}$; 1 cycle of $94^{\circ} \mathrm{C}$ for $2 \mathrm{~min}$; 40 cycles of $94^{\circ} \mathrm{C}$ for $15 \mathrm{~s}, 58^{\circ} \mathrm{C}$ for 30 $\mathrm{s}$, and $68^{\circ} \mathrm{C}$ for $1 \mathrm{~min}$; then 1 cycle of $68^{\circ} \mathrm{C}$ for $9 \mathrm{~min}$. For direct sequencing, the resulting RT-PCR products were digested with exonuclease I and shrimp alkaline phosphatase (15) and then sequencing reactions were carried out in both directions using BigDye (version 3.1; Applied Biosystems). After ethanol precipitation, sequencing reactions were analyzed on an ABI 3100 Genetic Analyzer (Applied Biosystems). Base calling was carried out using SeqScape software (version 2.1; Applied Biosystems) and confirmed by visual inspection of sequence traces. Alignments were produced using ClustalX version 1.8 software (29).

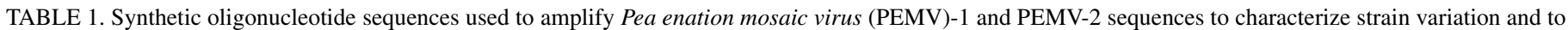
develop quantitative real-time reverse-transcription polymerase chain reaction assays

\begin{tabular}{|c|c|c|c|}
\hline Oligonucleotide name & Primer or probe & Sequence $\left(5^{\prime}-3^{\prime}\right)$ & Gene sequences amplified \\
\hline PEMV1 L1 411 ${ }^{\mathrm{a}}$ & Primer & AGGGCGGAATCTCATCTTTT & RNA-dependent RNA polymerase, partial cds \\
\hline PEMV1 R1 1000a & Primer & ATGACTGATCAGCCCGATTC & Hypothetical 34-kDa protein \\
\hline PEMV1 L2 2440a & Primer & CCCAAAGGACTCTCAAGCTG & RNA-dependent RNA polymerase, partial cds \\
\hline PEMV1 R2 2988 & Primer & ACGCTTGTTGCGAATCTTCT & Hypothetical 34-kDa protein \\
\hline PEMV1 L3 2967a & Primer & GGAGAAGATTCGCAACAAGC & RNA-dependent RNA polymerase, partial cds \\
\hline PEMV1 R3 3485a & Primer & CAGCTAGCCCCTGCATAAAG & $\ldots$ \\
\hline PEMV2 L1 1728 ${ }^{\mathrm{a}}$ & Primer & ACGGATTCGTCCGTTACAAG & RNA-dependent RNA polymerase, partial cds \\
\hline PEMV2 R1 2380a & Primer & CTTGTCATACAGCGCCTCAA & $\ldots$ \\
\hline PEMV2 L2 2361 ${ }^{\mathrm{a}}$ & Primer & TTGAGGCGCTGTATGACAAG & Intergenic region, long-distance movement protein \\
\hline PEMV2 R2 2983a & Primer & GCTTCAGTACGGAGCTGACC & $\ldots$ \\
\hline PEMV2 L3 3406 & Primer & GCATCCCAACAGCAATACCT & 3' Untranslated region \\
\hline PEMV2 R3 3855a & Primer & GTCGACAAGGTCATCCCCTA & $\ldots$ \\
\hline TqM_PEMV1_704F & Primer & TGCTCGGACTTACTCACCAAGA & RNA-dependent RNA polymerase \\
\hline TqM_PEMV1_813R & Primer & CATAGACTCCAGGACACCAGGAC & $\ldots$ \\
\hline TqM_PEMV1_Pft & Probe & 6-FAM CAGGCTTTATCTTGCGCTTCGCAGG-TAMRA & $\ldots$ \\
\hline TqM_PEMV2_3749F & Primer & GTCGGAGGGATCGCCAG & 3' Untranslated region \\
\hline TqM_PEMV2_3850R & Primer & CAAGGTCATCCCCTATCCCA & $\ldots$ \\
\hline TqM_PEMV2_Pft & Probe & 6-FAM CTCCCGCAGAGGGATAAGCTRTCTCC-TAMRA & $\ldots$ \\
\hline TqM_18S_F & Primer & CGTCCCTGCCCTTTGTACAC & Pisum sativum $18 \mathrm{~S}$ ribosomal RNA \\
\hline TqM_18S_R & Primer & CACTTCACCGGACCATTCAAT & $\ldots$ \\
\hline TqM_18S_Pft & Probe & VIC-CCGCCCGTCGCTCCTACCG-TAMRA & $\ldots$ \\
\hline
\end{tabular}

a Primer sequences designed using GenBank accessions NC_003629 (PEMV-1) and NC_003853 (PEMV-2). 
Sequences were trimmed to remove poor-quality base calls near the sequence run starts or ends. Sequences have been deposited with GenBank under accessions FJ620494 to FJ620516. Pairwise percent identity between aligned sequence fragments was calculated based on the number of invariable (monomorphic) sites counted in the "Polymorphism" dialog of DNASP version 4.0 (23). Mixed bases were coded as missing data. For each pairwise alignment, gaps and missing data due to mixed bases were excluded.

Multiplex qRT-PCR. Oligonucleotide primers and duallabeled probes for qRT-PCR were designed using Primer Express software (Applied Biosystems) to develop multiplex assays that amplify target PEMV genome-specific sequences simultaneously with an endogenous reference Pisum sativum $18 \mathrm{~S}$ ribosomal RNA sequence (GenBank accession U43011). Primer and probe sequences are presented in Table 1. Primers and all FAM-labeled PEMV probes were synthesized by Geneworks (Melbourne, Australia) and the VIC-labeled $18 \mathrm{~S}$ probe was synthesized by Applied Biosystems. qRT-PCR was conducted using fluorescent probe-based technology using an ABI PRISM 7700 Sequence Detection System for New Zealand-based work and a GeneAmp 7000 Sequence Detection System for Prosser, WA-based work (Applied Biosystems).

Multiplex qRT-PCR on samples, calibration curve standards, and controls were carried out in $25-\mu l$ reactions containing $1 \times$ Superscript III Platinum One-Step qRT-PCR System reaction mix (Invitrogen), primers and dual-labeled probes (Table 1), and ROX dye added to $0.5 \mu \mathrm{M}$. PEMV-1 or PEMV-2 primers were added to final concentrations of $400 \mathrm{nM}$ each and probes to $200 \mathrm{nM}$. $18 \mathrm{~S}$ rRNA endogenous control primers were added to final concentrations of $40 \mathrm{nM}$ (TqM_18S_F) and $80 \mathrm{nM}$ (TqM_18S_R) and the $18 \mathrm{~S}$ probe was added to $100 \mathrm{nM}$. Sample RNA (diluted to $\approx 2 \mathrm{ng} / \mu \mathrm{l}$ ) or a dilution of standard RNA was added to PCR reactions in 5- $\mu$ l volumes. Assays were carried out in 96-well optical PCR plates sealed with optical film (Applied Biosystems). The amplification protocol included an initial incubation at $50^{\circ} \mathrm{C}$ for $15 \mathrm{~min}$ for reverse transcription, then a $95^{\circ} \mathrm{C}$ incubation for $2 \mathrm{~min}$, followed by 40 cycles of $95^{\circ} \mathrm{C}$ for $30 \mathrm{~s}$ and $60^{\circ} \mathrm{C}$ for $30 \mathrm{~s}$. Calibration curves for $18 \mathrm{~S}$ and PEMV multiplex assays were developed for every run using infected pea leaf RNA dilutions (1:50 to 1:500,000). No-template controls (NTCs) were included in each run in duplicate. The cycle threshold $(\mathrm{Ct})$ parameters were recorded for each assay using the default thresholds calculated by Sequence Detection Systems 1.9 software (Applied Biosystems), except that the baseline data for $\mathrm{Ct}$ calculation were taken from cycles 3 to 8 due to early amplification of the $18 \mathrm{~S}$ sequences.

The relative accumulation of PEMV-1 and PEMV-2 genomes was quantified by normalizing against $18 \mathrm{~S}$ rRNA reference sequences, calculating mean normalized accumulation (MNA). As summarized by Simon (26), the efficiency (E) of qRT-PCR reactions was calculated from calibration curves where $E=10^{\left(-1 / \text { slope }^{2}\right.}$. Normalized accumulation (NA) was calculated as $\mathrm{NA}=$ $\mathrm{E}_{(\text {ref })}{ }^{(\mathrm{Ct}(\mathrm{ref}))} / \mathrm{E}_{\text {(test) }}{ }^{(\mathrm{Ct}(\text { test }))}$, and MNA was calculated as MNA = $\mathrm{E}_{(\text {ref })}\left(\mathrm{Ct}(\right.$ ref,mean) $) / \mathrm{E}_{(\text {test })}(\mathrm{Ct}($ test,mean)) .

Analysis of seed transmission. To analyze seed transmission by ELISA, mature pods showing symptoms typical of those caused by PEMV-1 were collected from infected Joel plants from the 2005 Central Ferry, WA field trial. One or two seeds were selected randomly from each pod and planted out into flats. Two weeks after the emergence of seedlings, 286 plants were tested using the direct ELISA method using anti-PEMV antisera that had been produced by Gus de Zoeten at the University of Wisconsin, Madison. Plants were also examined over a 4-week period for the appearance of visual symptoms.

Seed transmission was also analyzed by examining a grow-out of breeder seed collected from heavily infected plots for appearance of symptoms. A seed increase for pea cv. Medora was carried out in 250 small plots at Spillman Farm near Pullman, WA during the 2005 PEMV epidemic. Each of the 250 plots was heavily infected $(\geq 95 \%)$ with PEMV and showed stunting, distorted plant growth, characteristic windowing in the stipules, enations on the pods, and shriveled seed, symptoms typical of those associated with the virus. Seed harvested from these plots were bulked, then grown in a seed increase plot that resulted in $\approx 50,000$ plants in an aphid-free environment at Brawley, CA from November 2005 to April 2006. A smaller seed increase $(\approx 3,000$ plants) was grown out at Minot, ND, which was not an aphid-free environment. Plants in seed-increase plots were examined systematically for PEMV symptoms. Plots at Brawley were examined on 16 January 2006, while those at Minot were examined on 11 July 2006. The stage of plants at Brawley was prebloom/early bud and, at Minot, the plants were in early bloom.

Assessing infection levels. To estimate the number of plants that might have been missed during visual inspection of the field grow-out tests when no infection was detected for any of the plants in the sample, a percent confidence interval $(\mathrm{k})$ was calculated for the number of infected plants in the population $(\mathrm{N})$ and for a sample of size (n). The equation used here:

$$
\mathrm{n}=\mathrm{N}\left(1-\left(\frac{1-\mathrm{k}}{2}\right)^{\frac{1}{\mathrm{qN}}}\right)
$$

is adapted from the one described by Blythe (3). The equation has been adjusted to account for detection efficiencies (q) of $<1.0$ by modifying the effective population size from $\mathrm{N}$ to $\mathrm{qN}$.

\section{RESULTS}

Sequence analysis of PEMV RT-PCR fragments. Because sensitive and reliable qRT-PCR assays require that primers and probes bind to target sequences without mismatches, partial sequences of isolates from the 2005 PEMV epidemic in the Pacific Northwest were obtained using primers designed to three distinct regions of the PEMV-1 and PEMV-2 genomes (Table 1), followed by direct sequencing of RT-PCR products.

Nucleotide sequence alignments were produced from the PEMV1 and PEMV-2 RT-PCR products obtained from four infected plants. The resulting sequences were also compared with GenBank entries for PEMV-1 (NC_003629) and PEMV-2 (NC_003853 and AY714213) genomic sequences. The primary aim of this study was to explore accumulation of the PEMV-1 and PEMV-2 genomes in seed tissue; therefore, sequence variation in the isolates outside the RT-PCR amplified fragments was not explored further.

For the three sets of aligned sequences from PEMV-1 genomic RNA, pairwise percent nucleotide sequence identities are presented in Table 2. Aligned fragments are identified by sequence range numbers which relate to the PEMV-1 WSG strain genomic sequence (NC_003629). A high degree of sequence identity is apparent in the four Pacific Northwest isolates $(\geq 98.7 \%)$. These four isolates also are very similar to the Wisconsin strain WSG (NC_003629, 96.6 to $97.9 \%$ identity). This sequence has been used as a reference for numbering the sequenced fragments. Translations of the PEMV-1 sequence fragments were also compared (data not shown). The PEMV-1 411 to 970 fragment covers a region containing two open reading frames (ORFs), one encoding the hypothetical 34-kDa protein and the other the RNAdependent RNA polymerase. For the five PEMV-1 411 to 970 sequences being considered, corresponding variant amino acids are found at 15 of the 187 positions in the $34-\mathrm{kDa}$ protein ORF and 9 of the 186 positions in the RNA-dependent RNA polymerase ORF. In isolates WA3 and WA8, one base substitution resulted in a predicted in-frame stop codon. With respect to the four Pacific Northwest isolates, the amino acid sequence variation reflected the nucleotide sequence variation ( $\geq 97.8 \%$ identity). For the $34-\mathrm{kDa}$ protein ORF, the predicted amino acid sequence identities were less when comparing NC_003629 with the four 
Washington isolates (93.0 to 93.6\% identity). The PEMV-1 2443 to 2960 fragment covers a region containing the RNA-dependent RNA polymerase ORF. Only 2 of the 172 amino acid positions showed variation among all five sequences. The third fragment that was sequenced from PEMV-1 covers nucleotides 3099 to 3453 and encodes another portion of the RNA-dependent RNA polymerase. The predicted 118 amino acid sequences of this fragment were identical for all five isolates, in spite of the observed variation in the nucleotide sequences (Table 2).

Isolate-specific sequence variation was also apparent in the PEMV-2 RT-PCR products and included the detection of mixed bases (e.g., IUB base ambiguity codes $\mathrm{Y}, \mathrm{R}, \mathrm{K}, \mathrm{M}$, or W) at a number of positions. The presence of mixed bases suggests that these plants contained at least two PEMV-2 isolates. Pairwise nucleotide sequence identities are presented for the three sets of aligned sequences from PEMV-2 in Table 3. The PEMV-2 sequence fragments obtained from the four Washington isolates are compared with sequences from Wisconsin strain WSG (NC_003853) and the UK strain (AY714213). The PEMV-2 aligned fragments are identified by sequence range numbers that relate to the WSG strain (NC_003853). There was less sequence identity among these PEMV-2 sequence fragments (range 87.4 to $100 \%$ identity) than was observed for the PEMV-1 isolate sequence fragments. The variation in percent identity among the four Washington isolates was not noticeably different from the variation between these isolates and the WSG or UK isolates. Predicted translations of the PEMV-2 1834-2270 fragment sequences were compared for amino acid sequence variation (data not shown). These fragments are predicted to encode 145 amino acid peptides. Variant amino acid residues were found at 6 of the 145 positions, and pairwise comparisons indicated that there were 0 to 6 amino acid differences between isolates. In this fragment, isolate WA3 contained two ambiguous bases. Both base substitutions (AAA $\rightarrow$ GAA, AAG $\rightarrow$ GAG) result in codon changes $(\mathrm{K} \rightarrow \mathrm{E}, \mathrm{E} \rightarrow \mathrm{K})$. The two other PEMV-2 fragments that were sequence characterized contained only short coding regions; therefore, the predicted amino acid sequence alignments for these fragments were not examined.

Development of multiplex qRT-PCR assays. To enable relative quantification of PEMV genomes in pea tissues, multiplex qRT-PCR assays were developed for each PEMV genome. The fluorogenic 5' nuclease (TaqMan) technology was chosen because of the ability to multiplex reference and target sequences in the same reaction using different fluorescent dyes and, therefore, to obtain relative quantification. The alignments described above were used to design primers and probes used in qRT-PCR assays for both PEMV-1 and PEMV-2 genomes. The locations of suitable primers and probes for optimal conditions were constrained by the nucleotide sequence variation, particularly for PEMV-2. The final locations of the primers and probes on the PEMV-1 and PEMV-2 genomes are presented in Table 1. The PEMV-1 assay was developed using replicase sequences. Surprisingly, the PEMV-2 sequences that showed the greatest percent identity among isolates (Table 3 ) were in the $3^{\prime}$ untranslated region and, therefore, this was the best region for qRT-PCR assay design. Calibration curves were obtained using dilutions of RNA from infected stipules (data not shown). Linear relationships between $\mathrm{Ct}$ and $\log _{10}$ (RNA dilution) were observed over at least three orders of magnitude (1:50 to 1:50,000 dilutions). The PEMV1/18S rRNA multiplex calibration curves had the following characteristics: $18 \mathrm{~S}$ assay, $r^{2}=0.995, \mathrm{E}=1.667$; PEMV-1 assay, $r^{2}=0.989, \mathrm{E}=1.668$. Similarly, the characteristics of the PEMV2/18S rRNA multiplex calibration curves were: $18 \mathrm{~S}$ assay, $r^{2}=$ $0.989, \mathrm{E}=1.751$; PEMV-2 assay, $r^{2}=0.991, \mathrm{E}=1.838$. Absolute quantification of the PEMV viral genomes was not carried out in this study because we did not have purified PEMV genomic RNAs at hand.

Typically and reproducibly, the $18 \mathrm{~S}$ qRT-PCR assay described here resulted in $\mathrm{Ct}$ values of $\approx 30$ in our NTCs (data not shown). For most reactions, the effect of this nonspecific amplification of contaminating nucleic acids on relative quantification was negligible because the $\mathrm{Ct}$ values obtained for $18 \mathrm{~S}$ amplification in samples were 8.8 to 16.6 . However, there may have been a small effect on the $\mathrm{Ct}$ values obtained from the most dilute RNA extractions $(1: 500,000)$ used for constructing calibration curves. The Ct values obtained for NTCs for the $18 \mathrm{~S}$ assays multiplexed with PEMV-1 and PEMV-2 assays were, on average, 30.3 and 36.5 , respectively, while the $18 \mathrm{~S} \mathrm{Ct}$ values for the 1:500,000 diluted infected leaf RNA standard were only slightly lower at 28 to 29 and 30.5 to 32.5 , respectively. Such an effect is not apparent in the calibration curves, however.

qRT-PCR analysis of PEMV accumulation in infected tissues. The accumulation of PEMV-1 and PEMV-2 genomes was estimated in a small number of RNA extractions from infected tissue samples from three plants that included stipule, developing whole pea, pea seed coat, and pea embryo (Fig. 1). These results showed that PEMV-1 and PEMV-2 genomes accumulated in all tissues, with large relative differences in MNA between tissues. The PEMV genomes accumulated to high levels in stipule, whole pea, and seed coat but to much lower levels in pea embryo tissues.

TABLE 2. Pairwise comparisons of nucleotide sequence alignments for three regions of the Pea enation mosaic virus (PEMV)-1 genome

\begin{tabular}{|c|c|c|c|c|c|c|c|c|c|c|c|c|}
\hline & \multicolumn{4}{|c|}{ PEMV-1 411-970 } & \multicolumn{4}{|c|}{ PEMV-1 2443-2960 } & \multicolumn{4}{|c|}{ PEMV-1 3099-3453 } \\
\hline & WA1 & WA2 & WA3 & WA8 & WA1 & WA2 & WA3 & WA8 & WA1 & WA2 & WA3 & WA8 \\
\hline WSG & 97.0 & 97.0 & 96.8 & 96.8 & 97.5 & 97.9 & 97.9 & 97.9 & 96.6 & 96.6 & 96.9 & 96.6 \\
\hline WA1 & $\ldots$ & 98.9 & 98.7 & 98.7 & $\ldots$ & 99.2 & 99.6 & 99.2 & $\ldots$ & 99.4 & 99.7 & 99.4 \\
\hline WA2 & $\ldots$ & $\ldots$ & 99.1 & 99.8 & $\ldots$ & $\ldots$ & 99.6 & 100 & $\ldots$ & $\ldots$ & 99.7 & 100 \\
\hline WA3 & $\ldots$ & $\ldots$ & $\ldots$ & 99.3 & $\ldots$ & $\ldots$ & $\ldots$ & 99.6 & $\ldots$ & $\ldots$ & $\ldots$ & 99.7 \\
\hline
\end{tabular}

${ }^{a}$ Sequence range numbers relate to the PEMV-1 WSG strain genomic sequence (NC_003629). The sequence identity percentages are shown.

TABLE 3. Pairwise comparisons of nucleotide sequence alignments for three regions of the Pea enation mosaic virus (PEMV)-2 genome

\begin{tabular}{|c|c|c|c|c|c|c|c|c|c|c|c|c|c|c|}
\hline & \multicolumn{5}{|c|}{ PEMV-2 1834-2270 } & \multicolumn{4}{|c|}{ PEMV-2 2394-2748 } & \multicolumn{5}{|c|}{ PEMV-2 3495-3855 } \\
\hline & UK strain & WA1 & WA2 & WA3 & WA8 & UK strain & WA2 & WA3 & WA8 & UK strain & WA1 & WA2 & WA3 & WA8 \\
\hline WSG & 96.6 & 94.3 & 92.0 & 93.6 & 92.0 & 97.5 & 89.1 & 87.4 & 89.1 & 97.8 & 96.1 & 95.2 & 96.4 & 95.2 \\
\hline UK strain & $\ldots$ & 95.9 & 93.4 & 94.5 & 93.4 & $\ldots$ & 89.4 & 88.8 & 89.1 & $\ldots$ & 96.9 & 96.3 & 97.0 & 96.3 \\
\hline WA1 & $\ldots$ & $\ldots$ & 93.1 & 94.4 & 93.1 & $\ldots$ & nd & nd & nd & $\ldots$ & $\ldots$ & 96.9 & 96.9 & 96.9 \\
\hline WA2 & $\ldots$ & $\ldots$ & $\ldots$ & 92.4 & 100 & $\ldots$ & $\ldots$ & 89.3 & 98.9 & $\ldots$ & $\ldots$ & $\ldots$ & 97.5 & 98.6 \\
\hline WA3 & $\ldots$ & $\ldots$ & $\ldots$ & $\ldots$ & 92.4 & $\ldots$ & $\ldots$ & $\ldots$ & 88.8 & $\ldots$ & $\ldots$ & $\ldots$ & $\ldots$ & 97.5 \\
\hline
\end{tabular}

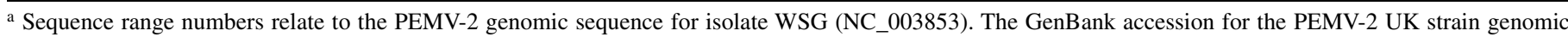
sequence is AY714213. The sequence identity percentages are shown; nd = not determined. 
On average, PEMV-1 and PEMV-2 genomic RNAs accumulated to $\approx 1,240 \times$ and $13,000 \times$ higher levels, respectively, in stipule than in embryo.

A larger study of PEMV genomic RNA accumulation in developing seed tissues from PEMV-infected plants was carried out using transplanted buffer row plants (cv. Joel) from the Central Ferry field trial. Tissues were dissected from nine pods from seven plants, resulting in 34 RNA extractions. The abundance of PEMV genomic RNA in extractions was characterized by multiplex qRT-PCR. MNA values for the PEMV-1 and PEMV-2 sequences as well as the relative abundance of PEMV genomes in seed tissues versus pod walls are presented in Table 4. The MNA values obtained for PEMV-1 and PEMV-2 in pod wall, seed coat, cotyledon, and embryo axis tissues are presented graphically in Figure 2.

As the results clearly show, PEMV-1 and PEMV-2 genomic RNAs accumulated to high amounts in all pod wall and seed coat samples. The relative abundance of the viral genomes in the seed coats was similar to those observed in pod walls. Pod walls and seed coats are maternal tissues; therefore, high titers of PEMV genomes are not surprising. PEMV-1 and PEMV-2 genomes were often detected in embryo tissues but at much lower levels. Lower amounts of these viral genomes accumulated in the embryo tissues, which were dissected into cotyledons (seven extractions), embryo axes (seven extractions), and combined cotyledons and embryo axes (two extractions) (Table 4). PEMV-1 was not detected in embryo axis extractions from three plant or pod samples (SH2/pod1, SH4, and SH5) (Table 4) or from one cotyledon and embryo axis extraction (SH3). PEMV-2 was not detected in extractions from one cotyledon and embryo axis (SH3) or one embryo axis (SH5). In all cases where PEMV-1 was detected, concentrations were greater in the cotyledons than in the embryo axis. Therefore, this qRT-PCR analysis has shown that the PEMV1 and PEMV-2 genomes can be seedborne.

Seed transmission was not observed. Seed produced from heavily PEMV-infected Medora plants (estimated incidence $\geq 95 \%$ ) grown during the 2005 field season provided the opportunity to examine the incidence of seed transmission of PEMV. In these evaluations, no visual PEMV symptoms were observed upon thorough examination of $\approx 50,000$ Medora plants in the aphid-free environment in Brawley, CA. Subsequently, an additional $900 \mathrm{~g}$ $(\approx 3,000$ seeds) of Medora seed were grown under field conditions at Minot, ND in 2006 and inspected. Similarly, no plants were observed with PEMV symptoms at this location.

Based on the 50,000 seeds planted at Brawley, the maximum number of infected plants that may have escaped detection (with 99 or $95 \%$ confidence) under two different assumptions of detection efficiency ( 99 or $90 \%$ ) was calculated. The calculation indicates that the maximum number of symptomatic plants in this trial would have been 5.9 with $99 \%$ confidence, even if the detection efficiency were only $90 \%$. Therefore, the maximum percent seed transmission that could have gone undetected under the assumptions of $90 \%$ detection and $99 \%$ confidence was $\approx 0.012 \%$.

A smaller experiment was conducted using 286 seedlings germinated from seed harvested from infected Joel pods. No symptoms were observed on the seedlings at 27 days postgermination and PEMV was not detected by ELISA (data not shown).

\section{DISCUSSION}

Partial PEMV-1 and PEMV-2 nucleotide sequences have been determined for three regions of each viral genome by direct sequencing of RT-PCR products amplified from four infected plants from the 2005 Pacific Northwest PEMV epidemic, revealing the presence of at least four different isolates of each virus. These sequence data were used to guide the development of primers and probes for PEMV-1- and PEMV-2-specific qRT-PCR assays. Analysis of the nucleotide sequence variation showed in particular that the PEMV-2 sequences characterized from this epidemic were quite variable, with pairwise sequence identities of 88.8 to $100 \%$. A feature of the variation in the PEMV-2 sequences was the presence of mixed bases at some positions in the sequences, indicating that at least two PEMV-2 isolates were present in these plants.

In-frame stop codons were found in the putative RNA-dependent RNA polymerase sequences for PEMV-1 (in the 411 to 970 fragment) for isolates WA3 and WA8 (GenBank accessions FJ620500 and FJ620501), based on comparison with the PEMV-1 complete genome sequence (NC_003629). These sequence variants may result in truncated translation products. However, the full PEMV-1 RNA-dependent RNA polymerase is a translation fusion between two ORFs (9); therefore, alternative translation strategies may apply to produce a fully functional RNAdependent RNA polymerase for these isolates. Otherwise, the PEMV-2 RNA-dependent RNA polymerase may function to replicate PEMV-1 sequences, although this has not been demonstrated to date (12).

The development of qRT-PCR assays to detect PEMV-1 and PEMV-2 genomes and their use to estimate the relative amounts of these genomic RNAs in developing seed tissues has been described in this article. As a consequence, we have shown that the PEMV-1 and PEMV-2 genomes are seedborne. Relative quantification was achieved in multiplex assays by comparing the $\mathrm{Ct}$ values obtained from the PEMV-1 or PEMV-2 qRT-PCR with the $\mathrm{Ct}$ values obtained from an endogenous control 18S rRNA qRT-PCR. One complication of using the $18 \mathrm{~S}$ rRNA as an endogenous qRT-PCR control was late amplification of sequences from our NTCs. BLAST searches revealed that the $18 \mathrm{~S}$ primer and probe sequences bind nearly perfectly to many bacterial $16 \mathrm{~S}$ ribosomal RNA sequences. Therefore, we infer that amplification

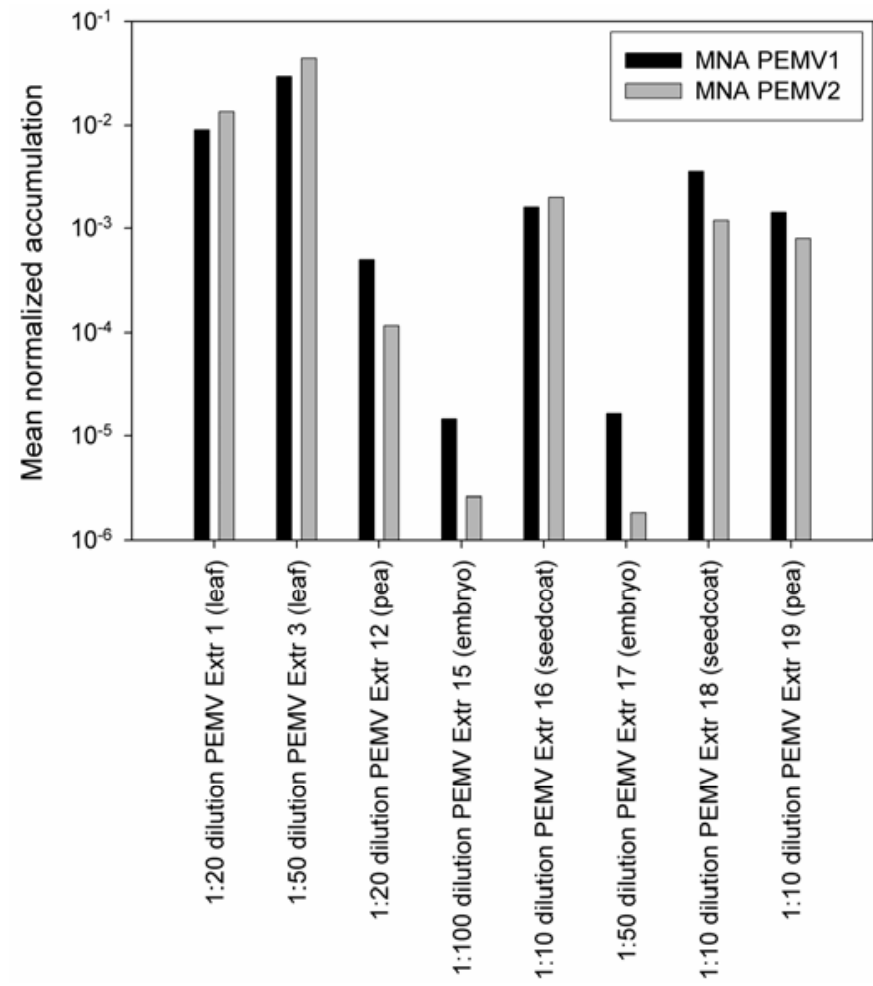

Fig. 1. Examination using multiplex quantitative real-time reverse-transcription polymerase chain reaction assays of the relative accumulation of Pea enation mosaic virus (PEMV)-1 and PEMV-2 genomic RNA in stipule, whole pea, seed coat, and embryo tissues, expressed as mean normalized accumulation (MNA). 
of the 18S assay in NTCs is due to the presence of bacterial RNA or DNA in the Invitrogen Superscript III Platinum One-Step qRTPCR System. The presence of bacterial DNA in Taq DNA polymerase preparations has been reported (2).

qRT-PCR assays to detect PEMV-1 and PEMV-2 have been described previously (28) using different primer and probe combinations, and without use of an endogenous reference sequence to enable relative quantification. Skaf and de Zoeten (27) used these assays to assess the relative abundance of PEMV1 and PEMV-2 wild-type and mutant RNAs in protoplasts and leaf tissues, and to examine the relationship between genome abundance and symptom severity.

The two recognized routes for embryo invasion by a plant virus are either through gametic fusion involving an infected gamete, which may be an egg or pollen cell, or through invasion after fertilization (32). The uneven patterns of PEMV genome accumulation that we observed in the dissected embryo tissues indicate that PEMV is likely to infect the embryo after fertilization because some embryos or parts of embryos remained free of viral RNA. Due to the high sensitivity of RT-PCR, the possibility also exists that PEMV-1 and PEMV-2 genomic RNA detected in cotyledons and embryo axes may have resulted from contami- nation rather than embryo invasion, even though great care was taken to avoid contamination during dissection. If the PEMV genomic RNA detected in these tissues was indeed the result of contamination, then the likelihood that PEMV is seed transmitted becomes even more remote than our current evidence indicates. Wang and Maule (32) showed that PSbMV, a virus that enters the pea embryo after fertilization, is unevenly distributed within embryo tissues, whereas pea embryos are uniformly infected with Pea early browning virus (PEBV), a virus that is detected in egg cells or pollen grains. Pollen transmission of PEMV has not been reported (27).

Previously, the only primary report of seed transmission of PEMV disease was published by Kovachevsky (16). This article reports that plants grown at the Central Seed Production Station in Birimirtsi, Bulgaria using seed from infected plants developed PEMV symptoms early, and that pea aphid or other aphids were not seen prior to observing symptoms. This suggests that these plants were grown in the field without aphid control, which introduces the possibility that aphid transmission of PEMV to these seedlings may have occurred. There have been no other reports or observations of seed transmission of PEMV in pea since the original article by Kovachevsky in 1978.

TABLE 4. Mean normalized accumulation (MNA) of Pea enation mosaic virus (PEMV)-1 and PEMV-2 genomic RNA in tissues from infected plants ${ }^{\mathrm{a}}$

\begin{tabular}{|c|c|c|c|c|}
\hline Plant, pod, tissue & $\begin{array}{l}\text { PEMV-1 } \\
\text { (MNA) }\end{array}$ & $\begin{array}{l}\text { PEMV1 relative abundance } \\
\text { versus podwall }\end{array}$ & $\begin{array}{l}\text { PEMV-2 } \\
\text { (MNA) }\end{array}$ & $\begin{array}{c}\text { PEMV2 relative abundance } \\
\text { versus podwall }\end{array}$ \\
\hline \multicolumn{5}{|l|}{ SH1, pod1 } \\
\hline Pod wall & $4.54 \times 10^{-3}$ & 1.0 & $2.43 \times 10^{-2}$ & 1.0 \\
\hline Seed coat & $3.92 \times 10^{-3}$ & $8.72 \times 10^{-1}$ & $8.47 \times 10^{-3}$ & $3.48 \times 10^{-1}$ \\
\hline Cotyledons & $3.09 \times 10^{-6}$ & $6.86 \times 10^{-4}$ & $2.58 \times 10^{-5}$ & $1.06 \times 10^{-3}$ \\
\hline Embryo axis $(n=3)$ & $4.52 \times 10^{-7}$ & $1.00 \times 10^{-4}$ & $1.79 \times 10^{-5}$ & $7.39 \times 10^{-4}$ \\
\hline Whole pea & $1.22 \times 10^{-4}$ & $2.71 \times 10^{-2}$ & $9.21 \times 10^{-4}$ & $3.79 \times 10^{-2}$ \\
\hline \multicolumn{5}{|l|}{ SH1, pod2 } \\
\hline Cotyledons and embryo axis & $3.47 \times 10^{-4}$ & $\mathrm{n} / \mathrm{a}$ & $1.02 \times 10^{-3}$ & $\mathrm{n} / \mathrm{a}$ \\
\hline Embryo axis $(n=1)$ & $4.52 \times 10^{-7}$ & $\mathrm{n} / \mathrm{a}$ & $1.79 \times 10^{-5}$ & $\mathrm{n} / \mathrm{a}$ \\
\hline \multicolumn{5}{|l|}{ SH2, pod1 } \\
\hline Pod wall & $6.77 \times 10^{-3}$ & 1.0 & $1.43 \times 10^{-2}$ & 1.0 \\
\hline Seed coat & $5.83 \times 10^{-4}$ & $8.61 \times 10^{-2}$ & $1.09 \times 10^{-2}$ & $7.64 \times 10^{-1}$ \\
\hline Cotyledons & $4.91 \times 10^{-6}$ & $7.25 \times 10^{-4}$ & $1.97 \times 10^{-4}$ & $1.38 \times 10^{-2}$ \\
\hline Embryo axis $(n=1)$ & nd & nd & $1.01 \times 10^{-4}$ & $7.05 \times 10^{-3}$ \\
\hline \multicolumn{5}{|l|}{$\mathrm{SH} 2, \operatorname{pod} 2$} \\
\hline Pod wall & $3.50 \times 10^{-3}$ & 1.0 & $1.87 \times 10^{-2}$ & 1.0 \\
\hline Seed coat & $1.37 \times 10^{-4}$ & $3.91 \times 10^{-2}$ & $1.40 \times 10^{-3}$ & $7.48 \times 10^{-2}$ \\
\hline Seed coat and cotyledons ${ }^{b}$ & $5.19 \times 10^{-6}$ & $1.43 \times 10^{-3}$ & $4.09 \times 10^{-5}$ & $2.19 \times 10^{-3}$ \\
\hline \multicolumn{5}{|l|}{ SH3 } \\
\hline Pod wall & $6.78 \times 10^{-3}$ & 1.0 & $5.96 \times 10^{-3}$ & 1.0 \\
\hline Seed coat & $1.50 \times 10^{-2}$ & 2.22 & $5.25 \times 10^{-3}$ & $8.80 \times 10^{-1}$ \\
\hline Cotyledons & $1.43 \times 10^{-5}$ & $2.11 \times 10^{-3}$ & $1.05 \times 10^{-4}$ & $1.77 \times 10^{-2}$ \\
\hline Cotyledons and embryo axis & nd & nd & nd & nd \\
\hline Whole pea & $3.20 \times 10^{-3}$ & $4.73 \times 10^{-1}$ & $3.35 \times 10^{-3}$ & $5.62 \times 10^{-1}$ \\
\hline \multicolumn{5}{|l|}{$\mathrm{SH} 4$} \\
\hline Pod wall & $5.12 \times 10^{-3}$ & 1.0 & $2.92 \times 10^{-2}$ & 1.0 \\
\hline Seed coat & $6.41 \times 10^{-3}$ & 1.25 & $3.80 \times 10^{-2}$ & 1.30 \\
\hline Cotyledons & $1.00 \times 10^{-5}$ & $1.96 \times 10^{-3}$ & $1.24 \times 10^{-4}$ & $4.23 \times 10^{-3}$ \\
\hline Embryo axis $(n=1)$ & $4.44 \times 10^{-6}$ & $8.68 \times 10^{-4}$ & $2.31 \times 10^{-4}$ & $7.90 \times 10^{-3}$ \\
\hline Embryo axis $(n=1)$ & nd & nd & $1.97 \times 10^{-4}$ & $6.75 \times 10^{-3}$ \\
\hline \multicolumn{5}{|l|}{ SH5 } \\
\hline Pod wall & $4.12 \times 10^{-3}$ & 1.0 & $4.74 \times 10^{-2}$ & 1.0 \\
\hline Seed coat & $7.35 \times 10^{-3}$ & 1.78 & $2.04 \times 10^{-2}$ & $4.30 \times 10^{-1}$ \\
\hline Cotyledons & $4.09 \times 10^{-6}$ & $9.91 \times 10^{-4}$ & $2.43 \times 10^{-5}$ & $5.13 \times 10^{-4}$ \\
\hline Embryo axis $(n=1)$ & nd & nd & nd & nd \\
\hline \multicolumn{5}{|l|}{ SH6 } \\
\hline Pod wall & $1.73 \times 10^{-2}$ & 1.0 & $5.65 \times 10^{-2}$ & 1.0 \\
\hline Seed coat & $1.15 \times 10^{-3}$ & $6.65 \times 10^{-2}$ & $9.06 \times 10^{-3}$ & $1.58 \times 10^{-1}$ \\
\hline Cotyledons & $7.79 \times 10^{-6}$ & $4.49 \times 10^{-4}$ & $7.64 \times 10^{-5}$ & $1.33 \times 10^{-3}$ \\
\hline Embryo axis & $1.15 \times 10^{-6}$ & $6.65 \times 10^{-5}$ & $1.90 \times 10^{-5}$ & $3.30 \times 10^{-4}$ \\
\hline \multicolumn{5}{|l|}{ SH7 } \\
\hline Pod wall & $5.26 \times 10^{-2}$ & 1.0 & $2.95 \times 10^{-2}$ & 1.0 \\
\hline Seed coat & $5.49 \times 10^{-3}$ & $1.04 \times 10^{-1}$ & $1.85 \times 10^{-2}$ & $6.28 \times 10^{-1}$ \\
\hline Cotyledons & $7.28 \times 10^{-6}$ & $1.39 \times 10^{-4}$ & $6.26 \times 10^{-5}$ & $2.12 \times 10^{-3}$ \\
\hline Embryo axis & $1.53 \times 10^{-6}$ & $2.92 \times 10^{-5}$ & $1.09 \times 10^{-5}$ & $3.69 \times 10^{-4}$ \\
\hline
\end{tabular}

a Abbreviations: $\mathrm{n} / \mathrm{a}=$ not tested and $\mathrm{nd}=$ not detected.

b A small amount of seed coat was retained on dissected cotyledons. 
As discussed above, we did not obtain any evidence for seed transmission of PEMV. For most plant viruses (an exception is TMV) (4), seed transmissibility requires embryo invasion, following which the virus must survive seed maturation, desiccation, and germination to infect the emerging seedling (19). Seedborne viruses are characterized by embryo invasion but seed transmission is not observed.

Although the complete mechanism of plant viral seed transmission is not fully understood, factors that affect seed transmissibility include plant genotype, virus strain, the presence of other plant viruses, and environmental factors. Host genotype has been shown to affect seed transmission of BSMV due to a single recessive genetic locus that confers resistance to BSMV transmission (5). Virus strains have been shown to affect seed transmission rate in BSMV (13). Transmission of PSbMV is also dependent on host genotype, and Wang and Maule (31) suggested that multiple maternal genes may be involved. Infection of plants with two different viruses can also result in enhanced seed transmission. For example, double infection of Arabidopsis thaliana with Turnip yellows mosaic virus (TYMV) and TMV results in a higher frequency of TYMV seed transmission than is obtained from TYMV infection alone (7). In cowpea, plants double infected with Bean southern mosaic virus (SBMV) and Cowpea chlorotic mosaic virus resulted in a higher seed transmission rate than was obtained from plants infected with SBMV alone (17).

The possibility that altering factors such as plant genotype, virus strain, presence of other viruses, or environmental factors would result in PEMV seed transmissibility cannot be completely ruled out because these possibilities have not been tested exhaustively. However, three of these factors varied in our study.

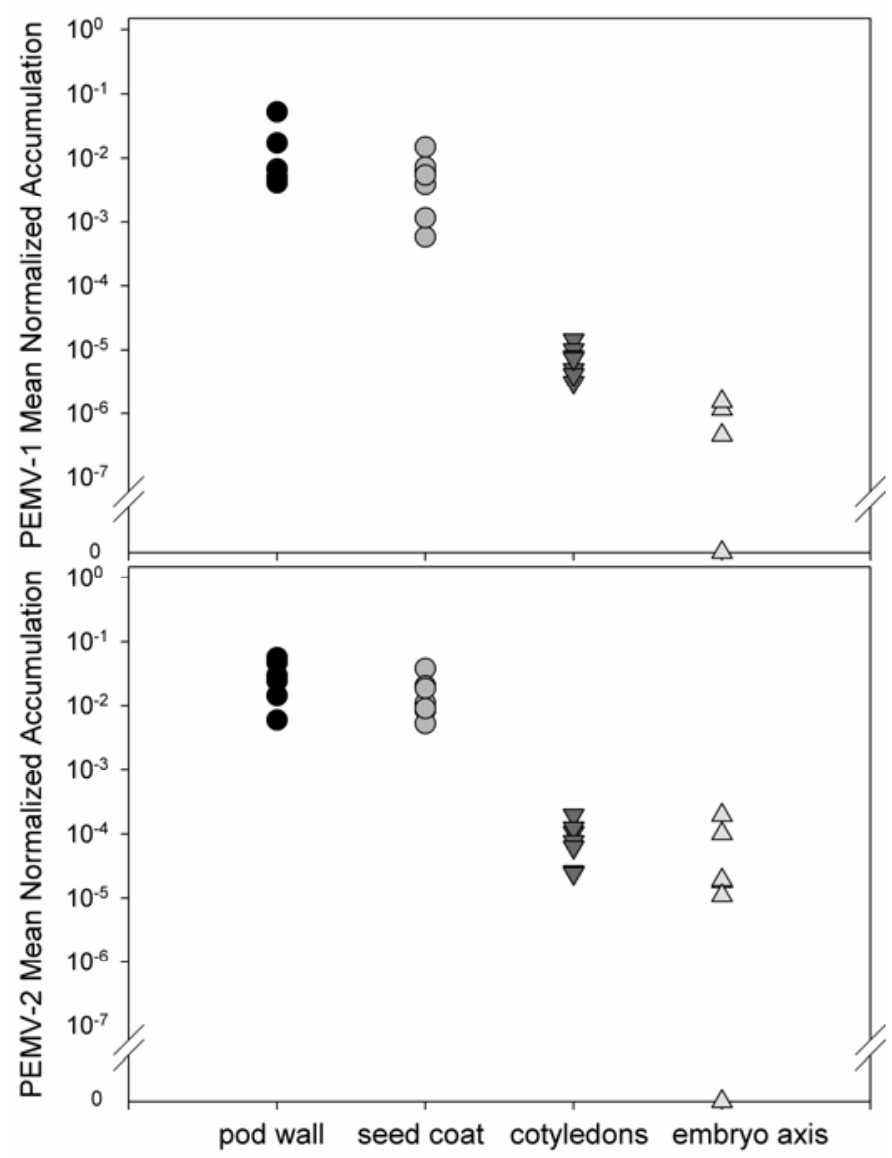

Fig. 2. Graphical representation of Pea enation mosaic virus (PEMV)-1 and PEMV-2 mean normalized accumulation (MNA) in pod wall, seed coat, cotyledon, and embryo axis tissues, which were calculated in comparison with endogenous $18 \mathrm{~S}$ rRNA from multiplexed quantitative real-time reversetranscription polymerase chain reactions.
Plants of two pea genotypes, Medora and Joel, were all grown from seed originating from infected plants and examined for evidence of PEMV disease, and no seed transmission was observed. Likewise, a number of different PEMV isolates were present in the naturally occurring 2005 virus epidemic, as demonstrated by our limited sequence analysis. Other pea viruses, including Bean leafroll virus and Pea streak virus, also were present during the epidemic at the Pullman and Central Ferry, WA sites (R. Larsen, unpublished data), although neither virus is seed transmitted. Plants that only displayed PEMV symptoms were selected for RNA extraction and tissue dissection and to provide the seed for the 286 plants that were grown out and examined by ELISA for PEMV. Therefore, we did not deliberately test the effect of double virus infection, although the probability exists that some of the Medora plants that contributed seed for the 50,000 -seed grow-out may have been infected with multiple viruses. Finally, we did not evaluate the effect of varying environmental conditions, particularly temperature, on seed transmission of the PEMV disease.

We conclude that the data presented here do not support the proposition cited in the literature $(16,27)$ that PEMV is seed transmitted. The qRT-PCR results, while showing that PEMV is seedborne, suggest that the absence of seed transmission may be due to the low abundance of the viral genomes in embryo tissues.

\section{ACKNOWLEDGMENTS}

G. Timmerman-Vaughan and R. Larsen contributed equally to this work. The research was funded by the New Zealand Ministry of Agriculture and Forestry and the New Zealand Foundation for Research Science and Technology. We thank R. Butler (Plant \& Food Research) for calculating confidence limits and S. Bulman and S. Zydenbos for critical comments that improved the manuscript.

\section{LITERATURE CITED}

1. Altschul, S. F., Gish, W., Miller, W., Myers, E. W., and Lipman, D. J. 1990. Basic local alignment search tool. J. Mol. Biol. 215:403-410.

2. Bach, H. J., Tomanova, J., Schloter M., and Munch J. C. 2002. Enumeration of total bacteria with genes for proteolytic activity in pure cultures and in environmental samples by quantitative PCR mediated amplification. J. Microbiol. Methods 49:235-245.

3. Blyth, C. R. 1986. Approximate binomial confidence limits. J. Am. Stat. Assoc. 81:843-855.

4. Broadbent, L. 1965. The epidemiology of tomato mosaic XI. Seedtransmission of TMV. Ann. Appl. Biol. 56:177-205.

5. Carroll, T. W., Gossel, P. L., and Hockett, E. A. 1979. Inheritance of resistance to seed transmission of barley stripe mosaic virus in barley. Plant Pathol. 69:431-433.

6. Clement, S. L. 2006. Pea Aphid Outbreaks and Virus Epidemics on Peas in the U.S. Pacific Northwest: Histories, Mysteries, and Challenges. Plant Health Progress. doi:10.1094/PHP-2006-1018-01-RV.

7. de Assisi-Filho, F. M., and Sherwood, J. L. 2000. Evaluation of seed transmission of Turnip yellow mosaic virus and Tobacco mosaic virus in Arabidopsis thaliana. Virology 90:1233-1238.

8. Demler, S. A., and de Zoeten, G. A. 1989. Characterization of a satellite RNA associated with pea enation mosaic virus. J. Gen. Virol. 70:10751084.

9. Demler, S. A., and de Zoeten, G. A. 1991. The nucleotide sequence and luteovirus-like nature of RNA 1 of an aphid non-transmissible strain of pea enation mosaic virus. J. Gen. Virol. 72:1819-1834.

10. Demler, S. A., Rucker, D. G., and de Zoeten, G. A. 1993. The chimeric nature of the genome of pea enation mosaic virus: The independent replication of RNA 2. J. Gen. Virol. 74:1-14.

11. Demler, S. A., Rucker, D. G., Mooruddin, L., and de Zoeten, G. A. 1994. Replication of the satellite RNA of pea enation mosaic virus is controlled by RNA 2-encoded functions. J. Gen. Virol. 75:1399-1406.

12. de Zoeten, G. A., and Skaf, J. S. 2001. Pea enation mosaic and the vagaries of a plant virus. Adv. Virus. Res. 67:323-350.

13. Edwards, M. 1995. Mapping of the seed transmission determinants of barley stripe mosaic virus. Mol. Plant-Microbe Interact. 8:906-915.

14. Havelda, Z., and Maule, A. J. 2000. Complex spatial responses to cucumber mosaic virus infection in susceptible Cucurbita pepo cotyledons. Plant Cell 12:1975-1985. 
15. Ibrahim, A., Hofman-Bang, J., and Ahring, B. K. 2001. Amplification and direct sequence analysis of the $23 \mathrm{~S}$ rRNA gene from thermophilic bacteria. BioTechniques 30:414-416.

16. Kovachevsky, I. 1978. Investigations on the pea enation mosaic virus. Rastenievud. Nauki 15:108-114.

17. Kuhn, C. W., and Dawson, W. O. 1973. Southern bean mosaic virus in single and double infections of cowpea. Phytopathology 63:1380-1385.

18. Larsen, R. C. 2001. Pea enation mosaic virus. Page 36 in: Compendium of Pea Diseases and Pests, 2nd ed. J. M. Kraft and F. L. Pfleger, eds. American Phytopathological Society, St. Paul, MN.

19. Maule, A. J., and Wang, D. 1996. Seed transmission of plant viruses: a lesson in biological complexity. Trends Microbiol. 4:153-158.

20. Mink, G. I. 1993. Pollen and seed-transmitted viruses and viroids Annu. Rev. Phytopathol. 31:375-402.

21. Murant, A. F., Robinson, D. J., and Taliansky, M. E. 1998. Groundnut rosette virus. CMI/AAB Descriptions of Plant Viruses No. 355.

22. Roberts, I. M., Wang, D., Thomas, C. L., and Maule, A. J. 2003. Pea seedborne mosaic virus seed transmission exploits novel symplastic pathways to infect the pea embryo and is, in part, dependent upon chance. Protoplasma 222:31-43.

23. Rozas, J., Sanchez-Delbarrio, J.C., Messeguer, X., and Rozas, R. 2003. DnaSP, DNA polymorphism analyses by the coalescent and other methods. Bioinformatics 19:2496-2497.

24. Rozen S., and Skaletsky, H. J. 2000. Primer3 on the WWW for general users and for biologist programmers. Pages 365-386 in: Bioinformatics
Methods and Protocols: Methods in Molecular Biology. S. Krawetz and S. Misener, eds. Humana Press, Totowa, NJ.

25. Ryabov, E. V., Fraser, G., Mayo, M. A., Barker, H., and Taliansky, M. 2001. Umbravirus gene expression helps potato leafroll virus to invade mesophyll tissues and to be transmitted mechanically between plants. Virology 286:363-372.

26. Simon, P. 2003. Q-gene software: processing quantitative real-time RTPCR data. Bioinformatics 19:1439-1440.

27. Skaf, J. S., and de Zoeten, G. A. 2000. Pea enation mosaic virus. CMI/AAB Description of Plant Viruses No. 372.

28. Skaf, J. S., Schultz, M. H., Hirata, H., and de Zoeten, G. A. 2000. Mutational evidence that the VPg is involved in the replication and not the movement of Pea enation mosaic virus-1. J. Gen. Virol. 81:11031109.

29. Thompson, J. D., Gibson, T. J., Plewniak, F., Jeanmougin, F. and Higgins, D. G. 1997. The ClustalX windows interface: Flexible strategies for multiple sequence alignment aided by quality analysis tools. Nucleic Acids Res. 24:4876-4882.

30. Wang, D., MacFarlane, S. A., and Maule, A. J. 1997. Viral determinants of pea early browning virus seed transmission. Virology 234:112-117.

31. Wang, D., and Maule, A. J. 1994. A model for seed transmission of a plant virus: genetic and structural analyses of pea embryo invasion by pea seedborne mosaic virus. Plant Cell 6:777-787.

32. Wang, D., and Maule, A. J. 1997. Contrasting patterns in the spread of two seed-borne viruses in pea embryos. Plant J. 11:1333-1340. 